\title{
Gas phase controlled deposition of high quality large-area graphene films $\dagger$
}

\author{
Shishir Kumar, ${ }^{a b}$ Niall McEvoy, ${ }^{a c}$ Tarek Lutz, ${ }^{a}$ Gareth P. Keeley, ${ }^{a b}$ Valeria Nicolosi, ${ }^{d}$ \\ Chris P. Murray, ${ }^{e}$ Werner J. Blau ${ }^{a c}$ and Georg S. Duesberg*ab
}

Received (in Cambridge, UK) 22nd September 2009, Accepted 13th January 2010

First published as an Advance Article on the web 29th January 2010

DOI: $10.1039 / b 919725 g$

\begin{abstract}
A gas phase controlled graphene synthesis resembling a CVD process that does not critically depend on cooling rates is reported. The controllable catalytic CVD permits high quality large-area graphene formation with deft control over the thickness from monolayers to thick graphitic structures at temperatures as low as $750{ }^{\circ} \mathrm{C}$.
\end{abstract}

Graphene has attracted enormous attention because of its exciting structural and electrical properties. ${ }^{1}$ Extremely high mobilities $^{2}$ and a tunable band gap $^{3}$ make graphene potentially useful for innovative approaches to electronics ${ }^{4}$ and sensing. ${ }^{5}$ For these applications a scalable and reproducible method for graphene production is required. Mechanical exfoliation of graphite $^{6}$ and decomposition ${ }^{7}$ of $\mathrm{SiC}$ surfaces upon thermal treatment have been the main sources for graphene, with limitations in quality and scalability. Solution-phase ${ }^{8}$ and solvothermal syntheses of graphene ${ }^{9}$ were a major improvement for processing, however for device fabrication, a reproducible method such as CVD yielding high quality films of controlled thickness is desirable. Recently, the formation of graphene under CVD-like conditions on $\mathrm{Ir},{ }^{10 a} \mathrm{Ru}^{10 b} \mathrm{Ni}^{11}$ and $\mathrm{Cu}^{12}$ surfaces has been reported. Nevertheless, these processes are not conventional CVD since they rely on precipitation of carbon upon cooling and require high-quality substrates, elevated temperatures $\left(\sim 1000{ }^{\circ} \mathrm{C}\right)$ and accurate control over cooling rates.

Here, we introduce a CVD process which produces high quality graphene with tunable thickness on Ni surfaces. We have synthesised large-area graphene films $\left(>1 \mathrm{~cm}^{2}\right)$ in a simple tubular CVD reactor using ethyne (acetylene) as precursor under varying CVD parameters. The nickel substrates were prepared by E-beam evaporation (Edwards Auto500) of Ni $(200 \mathrm{~nm})$ on thermally-grown silicon dioxide $(300 \mathrm{~nm})$. The substrates were introduced in a tube furnace heated to temperatures between $650{ }^{\circ} \mathrm{C}$ and $1000{ }^{\circ} \mathrm{C}$. After reduction

${ }^{a}$ Centre for Research on Adaptive Nanostructures and Nanodevices (CRANN), Dublin 2, Ireland

${ }^{b}$ School of Chemistry, Trinity College Dublin, Dublin 2, Ireland

${ }^{c}$ School of Physics, Trinity College Dublin, Dublin 2, Ireland

${ }^{d}$ Department of Materials, University of Oxford, Parks Road, Oxford, UK OX1 $3 P H$

${ }^{e}$ Intel Ireland Limited, Collinstown Industrial Park, Leixlip,

County Kildare, Ireland

† Electronic supplementary information (ESI) available: Electron diffraction images for graphene, EDX spectrum for transferred films, calculation for diffusivity of carbon in Ni at different temperatures and Raman spectra of graphene films for short dwell times. See DOI: $10.1039 / \mathrm{b} 919725 \mathrm{~g}$ by a mixture of hydrogen and argon $(1: 1)$ for $5 \mathrm{~min}$, Ar was shut off and acetylene was introduced, keeping the overall pressure between 0.5 and 5 Torr for various dwell times. The flow rate was nominally $60 \mathrm{sccm}$ for acetylene and $180 \mathrm{sccm}$ for hydrogen or argon, unless otherwise specified. The substrates were then cooled under nitrogen flow with rates exceeding $15{ }^{\circ} \mathrm{C} \mathrm{s}^{-1}$ or as slow as $0.15{ }^{\circ} \mathrm{C} \mathrm{s}^{-1}$. For reference, bare $\mathrm{SiO}_{2}$ substrates were also placed in the CVD chamber. A Zeiss Ultra FE SEM with an EDX detector was used for imaging the graphene layers directly on the substrates. Aberration-corrected HRTEM was carried out using an Oxford-JEOL JEM2200MCO FEGTEM/STEM fitted with two CEOS $\mathrm{C}_{\mathrm{s}}$ aberration correctors, operated at $80 \mathrm{kV}$. The samples for HRTEM were prepared by directly peeling off the carbon deposit from the substrate with a formvar film which then was deposited onto a TEM grid. Raman spectra were taken with a Jobin-Yvon Labram Raman spectrometer using an excitation wavelength of $633 \mathrm{~nm}$, with a probe size of $2 \mu \mathrm{m}$. Typically, five Raman spectra were taken on each sample to confirm homogeneity over the sample area. Graphene films were transferred by dissolving the $\mathrm{Ni}$ in $\mathrm{HCl}(\sim 5 \mathrm{M})$ and then dredging the films from the solution onto the desired substrates. A Veeco Dektak6 profilometer was used to measure the thickness of transferred films. The measurements were taken before and after the graphene layers were oxidised at a temperature of $800{ }^{\circ} \mathrm{C}$ in an open air furnace, in order to minimise any contribution from residual $\mathrm{Ni}$.

SEM images of graphene films display good homogeneity and show domains a few $\mu \mathrm{m}^{2}$ in area (Fig. 1a). Within the domains the films do not show any structural features, indicating the absence of defects. The TEM images (Fig. 1b and c) show the defect-free honeycomb lattice of a graphene monolayer, confirming the high quality of CVD-produced graphene. Electron diffraction shows a typical six-fold symmetry expected for graphene and graphite. The analysis of diffraction intensity ratio $I_{(0-110)} / I_{(1-210)}$ reveals a value of 1.38 proving that the flake is in fact a single layer. ${ }^{13}$ This is further supported by the Raman spectra 3A and 4D where the intensity ratio $I_{G} / I_{2 D}$ of the $G$ - and $2 D$-peaks at $\sim 1580 \mathrm{~cm}^{-1}$ and $\sim 2660 \mathrm{~cm}^{-1}$, respectively, is approximately 4 , indicative of graphene. These Raman spectra do not show any feature around $1330 \mathrm{~cm}^{-1}$, proving the perfect crystallinity of our graphene films within the probed area. The $D$-peak occurring in this region is indicative of defects and/or disorder in $\mathrm{sp}^{2}$ carbon systems ${ }^{14}$ (see supplementary information $\dagger$ ).

Fig. 2a depicts two homogeneous graphene films after transfer onto glass slides. The difference in thickness, apparent 


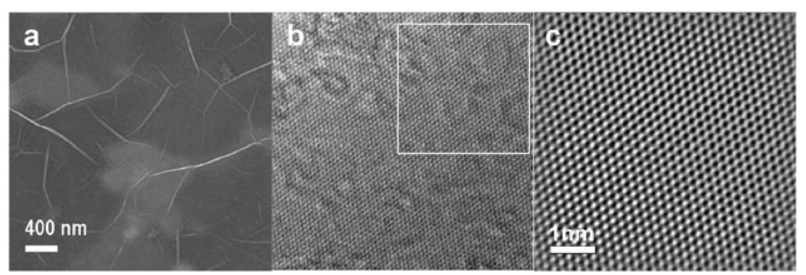

Fig. 1 (a) SEM image of a transferred graphene film. (b) Aberrationcorrected HRTEM image of a transferred graphene film grown by CVD. (c) Filtered HRTEM image of inset in (b), showing a perfect hexagonal graphene lattice.

from different transparencies, results from varying growth times. Fig. $2 \mathrm{~b}$ shows the change in thickness with growth time measured by profilometry. For comparison, the thickness of pyrolytic carbon (PyC) grown under identical conditions on catalytically inactive $\mathrm{SiO}_{2}$ substrates is also shown. The growth rate of graphene/graphite films on $\mathrm{Ni}$ is about $150 \mathrm{~nm} \mathrm{~h}^{-1}$ in the first $5 \mathrm{~min}$ and then continues at approximately $30 \mathrm{~nm} \mathrm{~h}^{-1}$. The growth rate of $\mathrm{PyC}$ on $\mathrm{SiO}_{2}$ is less than that of graphite on $\mathrm{Ni}$ in the initial stages, but has the same growth rate as $\mathrm{Ni}$ for longer dwell times.

For the CVD growth of graphitic carbon reported here, we propose a catalysed hetero-epitaxial deposition on $\mathrm{Ni}$, followed by homo-epitaxial growth to yield thicker graphite layers. The initial catalysis of graphene formation on $\mathrm{Ni}$ under similar conditions has been described earlier, ${ }^{15}$ and is thought to take place at step edges on the Ni surface. ${ }^{16}$ The graphitising effect of $\mathrm{Ni}$ is clearly confirmed by the Raman spectra in Fig. 3. Highly crystalline graphene monolayers (3(A)) as well as bulk graphite layers (3(B)) on $\mathrm{Ni}$ are observed, while in contrast the carbon film on inert $\mathrm{SiO}_{2}$ under the same conditions $(3(C))$ exhibits a large D-peak due to the nanocrystalline structure typical of PyC..$^{17}$ The catalysis of graphene formation takes place under similar conditions as those for the synthesis of carbon nanotubes on Ni nano-particles, however it is discontinuous, since a closed graphene layer puts a stop to further penetration of carbon feedstock into the $\mathrm{Ni}$ catalyst. Thus, thicker graphite films must be formed by homo-epitaxial growth on top of the initial graphene deposit. This two-step behaviour can be seen in the growth rates for graphitic deposits on Ni shown in Fig. 2b: the high initial growth rates are due to catalysed graphene formation, followed by slower, non-catalysed homo-epitaxial growth, with the same growth

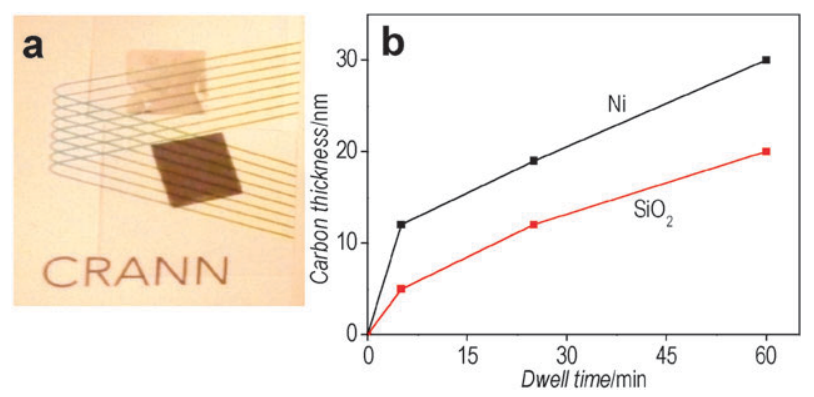

Fig. 2 (a) Photograph of graphitic films transferred onto glass slides with different thicknesses. (b) Thickness as a function of time of carbon deposits grown on $\mathrm{Ni}$ and $\mathrm{SiO}_{2}$ substrates at $950{ }^{\circ} \mathrm{C}$ and 5 Torr.

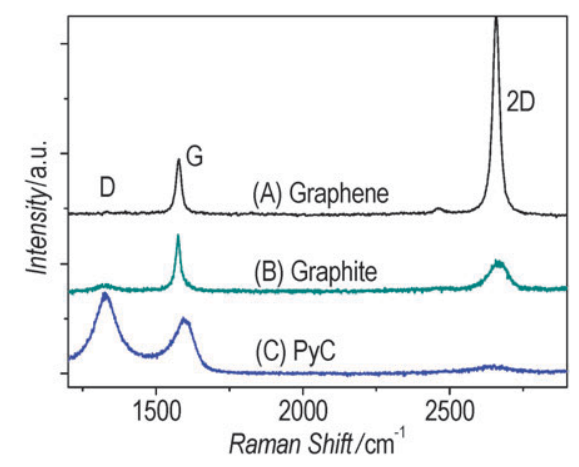

Fig. 3 Raman spectra (A) of graphene monolayer obtained on $\mathrm{Ni}$ after $30 \mathrm{~s}$ growth at $950{ }^{\circ} \mathrm{C}$ and 1 Torr, (B) of graphite on Ni after $1 \mathrm{~h}$ at $950{ }^{\circ} \mathrm{C}$ and 5 Torr, (C) of $\mathrm{PyC}$ on $\mathrm{SiO}_{2}$ under identical conditions as (B).

rates as for PyC. (Raman spectra for initial stages of growth are shown in supplementary information $\dagger$ ).

Growth models based on carbon segregation upon cooling cannot account for the graphite thicknesses that we observe, since the equilibrium solubility of carbon in $\mathrm{Ni}$ is less than $1 \%$ at $950{ }^{\circ} \mathrm{C}^{18}$ Assuming that a $200 \mathrm{~nm}$ Ni film is fully saturated with carbon and that all of this segregates upon cooling, a maximum of a $2 \mathrm{~nm}$ thick deposit can be expected, assuming similar lattice constants. This behaviour is observed upon slow cooling $\left(0.15^{\circ} \mathrm{C} \mathrm{s}^{-1}\right)$ of a substrate, which produces FLG as shown by Raman spectrum 4(A). This provides an estimate for the upper bound of carbon that can segregate from our $\mathrm{Ni}$ films. A possible contribution of segregation based growth in our other experiments can not be ruled out, but will be minimal as the carbon segregation is quenched for fast cooling rates, yielding thin graphene films deposited directly from the gas phase (Raman Spectrum 3(A)).

We further observed the formation of graphene at $750{ }^{\circ} \mathrm{C}$, which to the best of our knowledge, is the lowest temperature reported for graphene synthesis. ${ }^{19}$ The Raman spectrum 4(B) shows FLG grown at $750{ }^{\circ} \mathrm{C}$, where maximum rates for the decomposition of acetylene have been reported. ${ }^{20}$ The formation of graphene by segregation is unlikely at lower temperatures, since the diffusivity drops exponentially with temperature. The diffusivity of carbon in $\mathrm{Ni}$ is approximately 25 times lower than that at $950{ }^{\circ} \mathrm{C}$ (see supplementary information $\dagger$ ), where already a 2 -fold decrease of the diffusion time causes the suppression of graphene formation. ${ }^{11 a}$ Further, we were able to achieve control over graphene thickness by varying the flow rate of the precursor gas only, underlining a gas phase controlled formation of graphene. As shown in the Raman spectra (C) and (D) of Fig. 4, mono-layered graphene was synthesised with a very low precursor supply, while a higher flow resulted in FLG.

By varying growth times we have demonstrated that graphitic carbon of controllable thicknesses down to monolayer graphene can be obtained by CVD. The dependence of film thickness on dwell time and precursor flow rates and low temperature growth are not consistent with the segregationcontrolled growth reported previously and indicate heteroepitaxial graphene formation on Ni followed by homo-epitaxial deposition. Better understanding of the growth mechanism of 


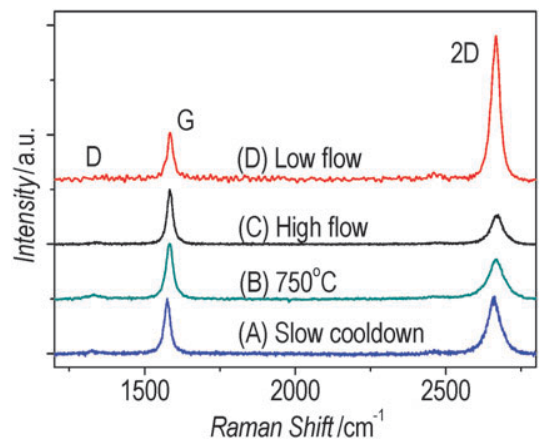

Fig. 4 Raman spectra (A) of graphene grown on $\mathrm{Ni}$ for $30 \mathrm{~s}$ at $950{ }^{\circ} \mathrm{C}, 1$ Torr and slow cooling $\left(<0.15{ }^{\circ} \mathrm{C} \mathrm{s}^{-1}\right)$, (B) of graphene grown at $750{ }^{\circ} \mathrm{C}$ and 1 Torr for $2 \mathrm{~min}$, (C) of few layer graphene and (D) of monolayer graphene obtained at $950{ }^{\circ} \mathrm{C}, 1$ Torr with a precursor flow of $20 \mathrm{sccm}$, and of $2 \mathrm{sccm}$ for 2 min respectively.

graphene will open a wealth of applications since it can be used for high-volume fabrication with fewer constraints on the substrates used and a considerable reduction in the thermal budget. Apart from film thickness control, CVD will also provide facile routes for the doping of graphene which will be vital for precise band gap tailoring.

SK and NME acknowledge the Embark Initiative via IRCSET scholarships. TL acknowledges EU for a Marie Curie Fellowship. GSD thanks SFI for funding in frame of the CSET program.

\section{Notes and references}

1 A. H. Castro Neto, N. M. R. Peres, K. S. Novoselov and A. K. Geim, Rev. Mod. Phys., 2009, 81, 109.

2 J. Chen, C. Jang, S. Xiao, M. Ishigami and M. S. Fuhrer, Nat. Nanotechnol., 2008, 3, 206.

3 Y. Zhang, T. Tang, C. Girit, Z. Hao, M. C. Martin, A. Zettl, M. F. Crommie, Y. R. Shen and F. Wang, Nature, 2009, 459, 820.

4 I. Meric, M. Y. Han, A. F. Young, B. Ozyilmaz, P. Kim and K. L. Shepard, Nat. Nanotechnol., 2008, 3, 654.

5 F. Schedin, A. K. Geim, S. V. Morozov, E. W. Hill, P. Blake, M. I. Katsnelson and K. S. Novoselov, Nat. Mater., 2007, 6, 652.

6 K. S. Novoselov, A. K. Geim, S. V. Morozov, D. Jiang, Y. Zhang, S. V. Dubonos, I. V. Grigorieva and A. A. Firsov, Science, 2004, 306, 666.

7 C. Berger, Z. Song, X. Li, X. Wu, N. Brown, C. Naud, D. Mayou, T. Li, J. Hass, A. N. Marchenkov, E. H. Conrad, P. N. First and W. A. de Heer, Science, 2006, 312, 1191.
8 (a) Y. Hernandez, V. Nicolosi, M. Lotya, F. M. Blighe, Z. Sun, S. De, I. T. McGovern, B. Holland, M. Byrne, Y. K. Gun'Ko, J. J. Boland, P. N. Niraj, G. Duesberg, S. Krishnamurthy, R. Goodhue, J. Hutchison, V. Scardaci, A. C. Ferrari and J. N. Coleman, Nat. Nanotechnol., 2008, 3, 563; (b) M. Lotya, Y. Hernandez, P. J. King, R. J. Smith, V. Nicolosi, L. S. Karlsson, F. M. Blighe, S. De, Z. Wang, I. T. McGovern, G. S. Duesberg and J. N. Coleman, J. Am. Chem. Soc., 2009, 131(10), 3611.

9 (a) V. C. Tung, M. J. Allen, Y. Yang and R. B. Kaner, Nat. Nanotechnol., 2009, 4, 25; (b) W. Qian, R. Hao, Y. Hou, Y. Tian, C. Shen, H. Gao and X. Liang, Nano Res., 2009, 2, 706.

10 (a) J. Coraux, A. T. N'Diaye, M. Engler, C. Busse, D. Wall, N. Buckanie, F. M. Z. Heringdorf, R. V. Gastel, B. Poelsema and T. Michely, New J. Phys., 2009, 11, 023006; (b) P. W. Sutter, J. Flege and E. A. Sutter, Nat. Mater., 2008, 7, 406.

11 (a) Q. Yu, J. Lian, S. Siriponglert, H. Li, Y. P. Chen and S. Pei, Appl. Phys. Lett., 2008, 93, 113103; (b) K. S. Kim, Y. Zhao, H. Jang, S. Y. Lee, J. M. Kim, K. S. Kim, J. Ahn, P. Kim, J. Choi and B. H. Hong, Nature, 2009, 457, 706; (c) A. Reina, X. Jia, J. Ho, D. Nezich, H. Son, V. Bulovic, M. S. Dresselhaus and J. Kong, Nano Lett., 2009, 9, 30.

12 X. Li, W. Cai, J. An, S. Kim, J. Nah, D. Yang, R. Piner, A. Velamakanni, I. Jung, E. Tutuc, S. K. Banerjee, L. Colombo and R. S. Ruoff, Science, 2009, 324, 1312.

13 (a) S. Horiuchi, T. Gotou, M. Fujiwara, R. Sotoaka, M. Hirata, K. Kimoto, T. Asaka, T. Yokosawa, Y. Matsui, K. Watanabe and M. Sekita, Jpn. J. Appl. Phys., 2003, 42, L1073; (b) J. C. Meyer, A. K. Geim, M. I. Katsnelson, K. S. Novoselov, G. Obergfell, S. Roth, C. Girit and A. Zettl, Solid State Commun., 2007, 143, 101.

14 (a) A. C. Ferrari and J. Robertson, Phys. Rev. B: Condens. Matter Mater. Phys., 2000, 61, 14095; (b) A. C. Ferrari, J. C. Meyer, V. Scardaci, C. Casiraghi, M. Lazzeri, F. Mauri, S. Piscanec, D. Jiang, K. S. Novoselov, S. Roth and A. K. Geim, Phys. Rev. Lett., 2006, 97, 187401.

15 (a) M. Yudasaka, R. Kikuchi, T. Matsui, Y. Ohki, M. Baxendale, S. Yoshimura and E. Ota, Thin Solid Films, 1996, 280, 117; (b) A. Johansson, J. Lu and J. Carlsson, Thin Solid Films, 1994, 252, 19.

16 H. S. Bengaard, J. K. Nørskov, J. Sehested, B. S. Clausen, L. P. Nielsen, A. M. Molenbroek and J. R. Rostrup-Nielsen, J. Catal., 2002, 209, 365.

17 G. Aichmayr, A. Avellan, G. S. Duesberg, F. Kreupl, S. Kudelka, M. Liebau, A. Orth, A. Sanger, J. Schumann and O. Storbeck, Japan Soc. Appl. Phys. Symposium on VLSI Technology, Kyoto, Japan, 2007, p. 186.

18 H. Ohtani, M. Hasebe and T. Nishizawa, Trans. Iron Steel Inst. Jpn., 1984, 24, 857.

19 S. Kumar, N. McEvoy, T. Lutz, G. Keeley, N. Whiteside, W. Blau and G. S. Duesberg, ECS Trans., 2009, 19, 175.

20 G. S. Duesberg, A. P. Graham, F. Kreupl, M. Liebau, R. Seidel, E. Unger and W. Hoenlein, Diamond Relat. Mater., 2004, 13, 354. 